\title{
La Agogé de la Universalidad
}

\section{The agoge of universality}

\author{
Mario Sobarzo Morales
}

Recibido: 10/04/2013 - Aceptado: 01/07/2013

\begin{abstract}
Platón se representa al filósofo como un hombre de gran memoria, de rápida percepción y afanoso de saber. Este hombre desprecia todo lo pequeño, su mirada se remonta siempre al aspecto de conjunto de las cosas y abarca desde una atalaya muy alta la existencia y el tiempo. (...) Es un "amigo y pariente" de la verdad, de la justicia, de la valentía, del dominio de sí mismo. Platón cree en la posibilidad de llegar a realizar este tipo de hombre por medio de una selección temprana e ininterrumpida, por obra de una educación ideal y por la madurez de los años.
\end{abstract}

Werner Jaeger

\section{Resumen}

El artículo aborda la educación como un tema propio del campo de la filosofía política. En su desarrollo trabaja los conceptos de Bildung y libertad, la educación del ciudadano y la emergencia de la libertad moderna. Para Hegel la educación ocupa un lugar central en el desarrollo de su filosofía, y la Universidad aparece como el lugar por excelencia de realización del espíritu universal del Pueblo. Por su parte, Platón demuestra su admiración por la agogé espartana, pues implica una disciplina necesaria para el desarrollo del carácter (ethos) de los ciudadanos particulares que conforman la comunidad política. A su vez para Aristóteles, el proceso pedagógico es un acto que pertenece a la comunidad, y expresa el momento de transición del futuro ciudadano entre el oikos y el ágora. Finalmente, Hegel ve en el mundo antiguo la normatividad necesaria para formar al funcionario del Estado Moderno.

Palabras clave: Agogé - educación - universidad - ciudadanía - ágora

\begin{abstract}
This article tackles education as a subject belonging to the political philosophy scope. It explores concepts such as Bildung and liberty, citizens' education and modern liberty. Education is placed at the core of Hegel's philosophy and the university is the place par-excellence for the realisation of the people's universal spirit. Plato shows admiration for the Spartan agogé as it implies the necessary discipline for personality development (ethos) of citizens who form a political community. For Aristotle, the educational process belongs to the whole community and it expresses the transition between oikos and agora. Finally, Hegel finds in the Ancient World the necessary normativity to educate the modern civil servant.
\end{abstract}

Key words: Agogé - education - university - citizenship - agora 


\section{Bildung y Libertad}

La educación es un tema absolutamente connatural al campo de la filosofía política desde sus orígenes. Esto es obvio si se considera que la transición entre el espacio social (familia) y el espacio político es realizada por la capacidad de la teoría de determinar la subjetividad de los "nuevos"1, al mismo tiempo que se reproduce el conocimiento necesario para operar la complejidad del sistema productivo, y se es capaz de incentivar la creatividad cognitiva (pensamiento). El problema de la educación, debido a ello, se refiere al verdadero sentido de ella (qué se enseña) y los fines que cumple.

En el caso de Hegel la educación ocupa un lugar central en el desarrollo de su filosofía, y la Universidad aparece como el lugar por excelencia de realización del espíritu universal del Pueblo -Volk- en concordancia con el desarrollo de la subjetividad individual que se forma en el amor a la universalidad. Hegel, como gran admirador de la cultura clásica desarrolla su modelo educacional desde este momento de desarrollo del Espíritu Absoluto. Dos conceptos se encuentran interrelacionados en las ideas que él expone: en primer lugar, la idea de Bildung, un término intraducible al español que viene de Bilden, que como lo señala la filósofa Carla Cordua:

(...) quiere decir formar, componer, producir, cultivar, entre otras cosas. El sustantivo Bildung designa tanto el proceso de formación y cultivo, como el producto de este proceso, la cultura o forma adquirida por la vida individual y colectiva, por la cosa conformada.

El propósito final de la Bildung de los individuos es "elevar su singularidad y su naturalidad (...) a la libertad formal y a la universalidad formal del conocimiento y la voluntad, cultivar (bilden) la subjetividad en su particularidad" (PhdR, 187). El proceso de la educación y la formación privan de su crudeza y barbarie (PhdR, 20 y 187C) al contenido instintivo de la voluntad natural, a la vez que liberan al

1 Para la referencia de los "nuevos" como concepto filosófico véase: ARENDT, Hannah. La Crisis en la Educación. En: Entre el Pasado y el Futuro. Ocho Ejercicios de Reflexión Política Ed. Península. España, 1996. 
individuo singular de la dependencia de su propia subjetividad arbitraria, abriéndole paso a las posibilidades de su pensamiento y de su voluntad. (...) ella (la Bildung) convierte la subjetividad universal vacía en subjetividad desarrollada, o conformada, cultivada en sus aspectos y potencialidades particulares. ${ }^{2}$

En segundo lugar, tiene que ver con el contenido universal bajo el que se moldea al sujeto, y que cala su sentido en la formación ética y cívica, es decir en las propias instituciones del Estado que son las encargadas de la Bildung, y cuya principal figura la representa la Universidad.

Para Hegel, como heredero filosófico del mundo clásico, la Bildung tiene una refencia directa en lo que Platón expone en la República y Aristóteles en la Política. Esto se debe a que es en la educación (Paideia) donde se forma al ciudadano, pero también, en estos autores, porque es aquí donde el ser humano se conecta con la universalidad del conocimiento filosófico. Si uno compara los objetivos de ambos autores con Hegel, la similitud es sorprendente:

La fidelidad y la obediencia en su profesión así como la obediencia respecto al destino y el autoolvido en su obrar tienen como fundamento la renuncia a la vanidad, a la presunción y al egoísmo respecto a lo que es necesario en y para sí.

El hombre que desempeña fielmente pequeños cometidos, se muestra capaz para otros de mayor alcance, porque ha mostrado obediencia, una renuncia a sus deseos, inclinaciones, fantasías. ${ }^{3}$

Sin embargo, hay algo muy característico de la relación entre los clásicos y Hegel. Ni Platón ni Aristóteles toman como referencia para el desarrollo de su idea educativa a la sociedad ateniense, pues les parece un modelo corrupto de entrada, al dejarle la educación de los futuros ciudadanos a esclavos y a la iniciativa privada. En más de un lugar Platón demuestra su admiración por la agogé espartana, como ya veremos. $1^{\circ}$, pues implica un control de Eros, el que bien encauzado se torna fundamento de base de una comunidad sana,

2 CORDUA, Carla. El Mundo Ético. España, 1997. pág. 97.

3 HEGEL, G.W. Escritos Pedagógicos. En: www.librodot.com. Pág. 112-113. 
y en $2^{\circ}$, pues, implica la disciplina necesaria para el desarrollo del carácter (ethos) de los ciudadanos particulares que conforman la comunidad política.

En el caso de Aristóteles, la relación es más clara aún. No sólo la virtud de los ciudadanos depende de un proceso de formación que parte en la costumbre y termina en las leyes, sino que además el proceso pedagógico es un acto que pertenece a la comunidad, y expresa el momento de transición del futuro ciudadano entre el oikos y el ágora.

Hegel muestra su admiración por la disciplina que implica aprender una formación humanística, en el sentido que la Modernidad le asigna al estudio de los clásicos y a la filología.

Por lo demás, falta aún, una observación final, que yo, sin embargo no he añadido, dado que acerca de ese punto todavía estoy en conflicto conmigo mismo, -a saber, que quizá toda la enseñanza de la filosofía en los Gimnasios podría parecer superflua, que el estudio de los Antiguos es el más adecuado para la juventud gimnasial y que según su sustancia constituye la verdadera introducción a la filosofía. ${ }^{4}$

Sin embargo, el proceso de construcción del concepto de Bildung no sólo contará con antecedentes del mundo clásico ${ }^{5}$, sino que dependerá en un sentido fundamental del desarrollo de la modernidad, en su vertiente ilustrada y romántica. Es sobre esta base, que Hegel presenta la idea de Universidad. En dicha institución cuajan los conceptos de formación ciudadana propia del mundo clásico, y las de libertad y autonomía propias de la modernidad. Es por ello que dividiré la presentación del concepto de Universidad en dos momentos. En el $1^{\circ}$, me enfocaré en mostrar los rasgos constituyentes de la agogé espartana y su influencia en las 2 grandes teorías del Estado de la Antigüedad greco-romana, y el modo en que Hegel las integra en su sistema teórico-político. En el $2^{\circ}$, haré lo mismo con la dialéctica ilustración-romanticismo, que Hegel intenta conciliar en su filosofía, y que tiene relación con el nacimiento de la Universidad de Berlín.

4 Ídem. Pág. 107.

5 La razón de ello es que el estudio de ambos queda convertido en erudición vacía por exceso de celo veritativo. 
Finalmente, explicitaré algunas interrogantes que deja en evidencia Hegel respecto al sentido de la Universidad en el presente.

\section{La Educación del Ciudadano}

La filósofa Carla Cordua muestra cómo el proceso de transición desde la voluntad natural al desarrollo del Estado (como realización de la universalidad determinada históricamente) se entronca en la capacidad de combinar el desarrollo del sujeto y la construcción de un modelo de Bildung adecuada para responder a las exigencias de la libertad y el Derecho.

Los instintos deberían ser sometidos a una purificación. (...) la razón de esta manera de proceder bien puede ser la siguiente: los elementos a partir de los cuales se desarrolla la voluntad natural (...) son momentos conscientes del desarrollo del espíritu, pero son aún subjetivos, esto es son más bien deficientes objetiva o racionalmente. Esto quiere decir diversas cosas, según el nivel o grado de la deficiencia. Pero, en general en tanto que subjetivo, el espíritu no se tiene más como relación interna consigo mismo. Le falta todavía el mundo que, procedente de su acción y de su tendencia a cumplirse como espíritu absoluto, lo realiza y le ofrece con ello cómo volver en sí desde lo otro, conociéndose y teniéndose consigo gracias a tal vuelta. ${ }^{6}$

Este carácter de la voluntad como negadora del mundo es parte central del desarrollo de la autoconciencia subjetiva. La acción negatriz permite al pensamiento instalarse en el plano de la autoconciencia, haciendo que el individuo devenga sujeto, y a partir de allí se construirá ese nosotros que es el Estado como espíritu de la Nación. Como lo muestra Bataille, siguiendo la lectura de Kojeve, el rasgo de autoconciencia del ser humano tiene que ver con la negatividad.

Al contrario del conocimiento que mantiene al hombre en una quietud pasiva, el Deseo lo torna in-quieto y lo empuja a la acción. Nacida del Deseo, la acción tiende a satisfacerlo, y sólo puede hacerlo por la "negación", la destrucción o por lo menos la transformación del objeto deseado (...) Así, toda acción es negatriz. Lejos de dejar lo dado tal como es, la 
acción lo destruye si no en su ser, por lo menos en su forma dada. Y toda negatividad negatriz por relación a lo dado es necesariamente activa. Mas la acción negatriz no es puramente destructiva. Porque si la acción que nace del Deseo destruye una realidad objetiva para satisfacerlo, crea en su lugar, en y por esta destrucción misma, una realidad subjetiva.?

Es por ello que el mundo antiguo es tan importante: en él se realiza la $1^{\text {a }}$ síntesis armónica entre el reconocimiento intersubjetivo y la Universalidad concreta (histórica) ${ }^{8}$.

Así como el primer paraíso fue el paraíso de la naturaleza humana, así éste es el más elevado, el segundo paraíso, el del espíritu humano que se muestra en su naturalidad, libertad, profundidad y serenidad más bellas, tal como la novia sale de su cámara. La primera magnificencia salvaje de su aparición en Oriente queda circunscrita por el esplendor de la forma y atemperada en orden a la belleza; su profundidad ya no reside en la confusión, en la aflicción o en la arrogancia, sino que se manifiesta en una claridad imperturbada; su serenidad no es un juego infantil, sino que se difunde sobre la melancolía que conoce la dureza del destino, pero sin ser desviada por ella de la libertad sobre sí y de la medida. Creo que no exagero cuando digo que quien no ha conocido las obras de los Antiguos ha vivido sin conocer la belleza. ${ }^{9}$

Es por ello que Hegel relaciona la educación con conceptos del mundo clásico. En el mundo Antiguo se manifiesta el paraíso del espíritu humano, el momento en que la comunidad se relaciona consigo misma en una espontaneidad creadora en el arte, la arquitectura, la filosofía, la política, la historia, la lógica, etc. Aprender de ella es fundamental para formar la Bildung. El conocimiento profundo de ella impregna de inspiración a la generación romántica, como lo recuerdan las obras

\footnotetext{
7 KOJÈVE, A. La Dialéctica del Amo y el Esclavo. Ed. Leviatán. Argentina, 2006. Págs. 10-11.

8 El Absoluto hegeliano es expresión de ese carácter que aparecía patentizado en la máscara trágica, en que el concepto se encarna en el hombre particular, y que explica el castigo por transgredir ese orden universal. Para un desarrollo más completo de la idea: Sobarzo, Mario. Anánkê. Historia y Necesidad. En Nombrar el Devenir. Filosofía de la Historia, Memoria y Política. Pablo Aravena (editor). Ediciones Escaparate. Concepción, Chile, 2009.

9 HEGEL. Op. Cit. Págs. 10-11.
} 
Discípulos en Sais de Novalis o Hiperión de Hölderlin, por nombrar sólo 2 obras representativas de este rasgo. Y Hegel no es distinto en esto a sus ex compañeros de Seminario con los que plantó un árbol en reconocimiento a la Revolución Francesa (Schelling y Hölderlin). La educación que se inspira en el mundo antiguo transmite ese amor a la libertad reconciliada con la necesidad, al querer el destino tanto como padecerlo. Es por ello que es fundamental la disciplina en su estudio, sin ella el conocimiento se queda en superficialidades. Hegel ve en el mundo antiguo la normatividad necesaria para formar al funcionario del Estado Moderno (adaptado a la racionalización, en términos de Weber).

Y para esta iniciación no es suficiente un conocimiento general, de carácter externo, de los Antiguos, sino que nos debemos entregar a ellos de cuerpo y alma para aspirar su atmósfera, sus representaciones, sus costumbres, incluso, si se quiere, sus errores y prejuicios, para familiarizamos con este mundo, el más bello que ha existido. (...) Al fijar nuestra morada en un tal elemento, sucede que no sólo todas las fuerzas del alma son estimuladas, desarrolladas y ejercitadas sino que él mismo constituye una materia peculiar, mediante la que nos enriquecemos y preparamos nuestra sustancia mejor.

(...) De la misma manera que las plantas no sólo ejercitan sus fuerzas reproductoras mediante el contacto con la luz y el aire, sino que en este proceso absorben a la vez su alimento, así también la materia en la que se desarrolla y ejercita el entendimiento y la capacidad anímica en general, debe constituir a la vez un alimento. No aquella así Ilamada materia útil, aquella materialidad sensible, tal como se ofrece inmediatamente al esquema representativo del niño, sino tan sólo el contenido espiritual, que posee valor e interés en y para sí mismo, es lo que fortalece el alma y le proporciona esta apoyatura independiente, esta interioridad sustancial, que es la madre del sosiego, de la sensatez, de la presencia y la lucidez del espíritu; este contenido convierte al alma que se ha educado tomándolo como pauta en un núcleo de valores autónomos, dotado de una finalidad absoluta, sólo la cual constituye el fundamento de una utilidad para todo y que es importante implantar a todos los niveles sociales. ${ }^{10}$ 
Pero, ¿qué aspectos le interesan a Hegel de la cultura clásica? En primer lugar, la capacidad de conciliación entre universalidad y particularidad que ya hemos descrito; en $2^{\circ}$, el modo en que esa conciliación se expresó en el arte, la religión, y la política, y que los filósofos van a estar obligados a pensar en el campo del Derecho a partir de Roma. Es por ello que las distintas manifestaciones son la expresión del Genio de un pueblo, es decir la expresión primigenia en que el Espíritu Absoluto toma conciencia de sí. Esto supone la capacidad de formar las voluntades individuales y volverlas colectivas. Esta era la función que cumplía la educación (Paideia) en Grecia, como lo mostró en forma amplia Werner Jaeger ${ }^{11}$. Pues, en ella se forma la areté.

Para Platón la reflexión respecto a esto aparece desde un texto fundamental de la transición entre la etapa de juventud (aporética) y la etapa media (teoría de las ideas), como es Protágoras. En dicho texto Sócrates y Protágoras se reconocen mutuamente al invertir sus posiciones teóricas: Sócrates termina aceptando que la virtud política (sophrosyne) es educable, mientras logra hacer dudar a Protágoras sobre la disciplina que lo puede hacer ${ }^{12}$. En Alcibíades, texto de dudosa datación, pero de absoluto apego en su concepto educativo a la filosofía tardía (Las Leyes ${ }^{13}$ ), se muestra cómo el gobierno sobre los otros supone el autoconocimiento necesario para tener un control sobre Eros. El peligro es latente en la medida que los filósofos, los llamados a gobernar son los que más lo tienen. Sin embargo, su modelo educativo en La República está tomado de los espartanos.

Como lo señala Vernant respecto a la Paideia espartana:

11 JAEGER, Werner. Paideia. FCE. México, 2002.

12 El texto podría ser una defensa de la aristocracia en la medida que a Sócrates, Protágoras le parece un estafador por cobrar por algo que no entiende, sin embargo, ese tema tan fundamental en el desprecio a otros sofistas, no es lo que marca el argumento de Sócrates. De hecho concuerda con Protágoras en una teoría muy moderna de la culpabilidad penal. E incluso le llega a reconocer que no es natural, con lo que se abre a la justificación de la igualdad democrática que Protágoras ha desarrollado en su interpretación del mito de Prometeo. Aristocracia, no nobleza, como va a quedar claro en el proceso de selección de la República.

13 Como lo recuerda Oscar Velásquez en una nota a su traducción del texto, el hecho es que Sócrates encuentra admirable este modelo de 4 maestros que forman al Emperador Persa en lo que la cultura occidental llegaría a reconocer como las virtudes cardinales. 
Su objetivo consiste en convertir al joven en adulto, cosa que implica cierta transformación, un verdadero cambio de estatuto, el acceso a una nueva condición de existencia. Al inculcar al joven la aspiración a la gloria personal y al mismo tiempo el sentido cívico, la Paideia aporta algo de lo que en principio estaba desprovista y que, por naturaleza, pertenece exclusivamente al adulto capaz de ejercitar con pleno derecho el conjunto de actividades ligadas a su estatuto de ciudadano. (...) Por lo que ésta supone de verdadera promoción del joven (...), adopta la forma de un sistema organizado de pruebas a las cuales el muchacho es sometido y que está obligado a superar con tal de convertirse en sí mismo, es decir, para adquirir esa identidad social. ${ }^{14}$

Es este rasgo dialéctico lo que Platón expone y que a Hegel le parece admirable como grado de identidad cívica. El amor a la patria nace en medio del descubrimiento de la propia autonomía y libertad. La preparación y el deseo de grandes cosas se unen a la tragedia de un destino injusto, y aun así aceptado con la frente en alto ${ }^{15}$. En el mundo antiguo se realiza la unidad, pero se hace a costa de la particularidad. El individuo es obligado a la trasgresión para cumplir con el Universal histórico, es por ello que la Tragedia expone magistralmente la falla de la decisión, necesaria para reconciliarse con el destino histórico ${ }^{16}$.

14 VERNANT, J.P. Entre la Vergüenza y la Gloria en: El Individuo, la Muerte y el Amor en la Antigua Grecia. Editorial Paidós. España, 2001. Pág. 169.

15 La inconmensurabilidad de la vida humana viene de algo que los griegos descubrieron: el hombre es libre. Ser libre significa que el ser humano marcha en el tiempo como si tuviera una venda sobre los ojos: no puede ver ni siquiera un segundo después del presente. La vida humana es trágica porque por mucho que el ser humano viva según certezas, las únicas que posee son la seguridad de su muerte y la evidencia práctica de no saber cómo controlar el tiempo. La educación que deja la tragedia es acerca de la libertad. Vivir acordes a la libertad es no pretender determinar las consecuencias de las decisiones, es jugar la vida a cada jugada, sólo considerando el valor que esto tiene en ella. Pero es, también, reconocer las consecuencias de la propia vida con el orgullo de haber tomado en las propias manos el destino, independiente de sus consecuencias.

Edipo sabía, conocía, su destino, pero eso no significaba su aceptación. Él se rebela frente a lo que debe suceder, y es en esa rebelión que hace que el destino suceda. Edipo es un héroe porque no le echa la culpa al destino, sino que decide asumir la responsabilidad sobre sus acciones: se ha liberado, incluso, del destino.

16 Si en ella no existe voluntad en el sentido de unidad entre quien realiza la acción y la acción misma. Si, a su vez, no hay unidad entre la determinación de la acción y el sujeto que la realiza: ¿en qué sentido la culpabilidad puede ser motivo de determinación del actor que realiza la acción? ¿No sería más bien una víctima que un 
El Héroe trágico educa a los ciudadanos en el cumplimiento del destino, y con ello sella la puerta a la realización de la subjetividad en el sentido que Hegel la busca como $2^{\circ}$ momento de la Bildung. La imagen del sacrificio ya no es posible en el mundo moderno. Pero, ¿cuál es el motivo de ello?

Como lo señala Pierre Aubenque ${ }^{17}$, Aristóteles identifica tres momentos en el desarrollo de la virtud moral necesaria para que exista identidad entre los fines objetivos (de la comunidad) y subjetivos. En primer lugar, comprender que la moral es parte del pathos (la pasión), y no sólo de las costumbres y el logos. Gracias a ello es posible construir una moral realista en los hechos, pero normativa en teoría. Lo que se nota, en $2^{\circ}$ lugar, en que la virtud, a pesar de ello es racional en su principio (orthos logos). Y por último, se manifiesta notoriamente en que lo que logran unir la pasión y la corrección, son una aristocracia en relación al autocontrol (sophrosyne ${ }^{18}$ ), para hacer posible la phronesis (prudencia) en acto, que es el spoudaios (aquel que posee prestigio en el sentido de reconocimiento a su sabiduría).

\section{Como lo ha recordado certeramente Michel Foucault:}

En algunos, esta extremada virtud era la señal visible del dominio que ejercían sobre sí mismos y, por consiguiente, del poder que eran dignos de asumir sobre los demás. ${ }^{19}$

De este modo, la Antigüedad expresa la realización de la Universalidad, pero también los límites de sus posibilidades de desarrollo. En ella la

culpable? Esta respuesta tiene una importancia fundamental para nuestro problema. La concepción trágica vista desde lo expuesto por Vernant asignaría culpabilidad en la medida que es una conjunción de dos formas de concebir al crimen: una arcaica en que él existe externa e independientemente a su causa (aitía) y que debe alejar al culpable, en la medida que él como autor del crimen contamina con su existencia y su hýbris todo lo que está cerca, y una surgida en el contexto de la legalización de la pólis, que requeriría definir la mácula por la intención, la premeditación y conocimiento de su realidad, esto es un acuerdo entre Sócrates y Protágoras en el diálogo homónimo de Platón.

17 AUBENQUE, Pierre. Aristóteles y el Liceo. En: La Filosofía Griega. Siglo XXI. Argentina, 2002.

18 La que pasará a ser la templanza en la tradición occidental.

19 FOUCAULT, Michel. Historia de la Sexualidad. Tomo 2. El Uso de los Placeres. Siglo XXI. España, 1994. Pág. 60. 
individualidad sólo puede ser sojuzgada como lo recuerda el caso de la educación lacedemonia (tiene una opinión distinta a Platón, pero semejante a Aristóteles ante ella) y la situación de los hijos en Roma. La descomposición de los vínculos entre libertad, virtud cívica y Religión pagana, dará como resultado:

En lugar de la integración con una vida que era la de su ciudad, el individuo se vuelve sobre sí mismo y se satisface con su propio goce. El gusto por la propiedad privada traduce, para Hegel, esa transformación. ${ }^{20}$

Es por ello que es necesario rastrear en la modernidad los rasgos que constituyen el $2^{\circ}$ momento de la realización de la idea de Bildung.

\section{La Emergencia de la Libertad Moderna}

Según el filósofo comunitarista Charles Taylor ${ }^{21}$, Hegel sería heredero de dos tradiciones desarrolladas en Alemania como modo de reacción a la tradición ilustracionista en su vertiente francesa.

Para esta corriente el hombre era considerado:

como sujeto y como objeto de un análisis científico objetivador. El enfoque de la objeción iba en contra de una visión del hombre como sujeto de deseos egoístas, al que la naturaleza y la sociedad sólo ofrecían los medios de realización. Era una filosofía utilitaria en su visión ética, atomista en su filosofía social, analítica en su ciencia del hombre, y buscaba una administración social científica para reorganizar el hombre y la sociedad y dar a los hombres la felicidad mediante una adaptación mutua perfecta. ${ }^{22}$

Las dos tradiciones que Hegel intentará reconciliar en su sistema, son el expresivismo desarrollado a partir del Sturm und Drang, y cuyo máximo exponente fue Herder, y por otro lado la vertiente de la libertad autodeterminada de Kant.

20 HYPPOLITE, J. Introducción a la Filosofía de la Historia de Hegel. Ed. Caldén. Uruguay, 1981. Págs. 35-36.

21 TAYLOR, Charles. Hegel y la Sociedad Moderna. Fondo de Cultura Económica. México, 1983.

22 Ídem. p. 14. 
Para el expresivismo el hombre es un ser análogo a una obra de arte, en el que todas las partes están relacionadas para dar nacimiento a un todo armónico, el cual no sólo funciona en relación a la propia estructura y vida personal, sino que permea esta situación a toda la sociedad y a la relación del hombre con lo natural, y por medio de éste con lo Divino.

La concepción de la Idea como síntesis de sujeto y objeto que constituye un fundamento a la vez subjetivo y objetivo del fin. La hegeliana lógica del concepto se apropia, para convertirla en realidad, la idea kantiana de un entendimiento arquetípico concebido como unidad de sujeto y objeto, de libertad y naturaleza, enfatizando con gran fuerza la superación, en ese entendimiento comprendido como real, de toda subjetividad externa al mundo objetivo y que imponga desde fuera sus fines al objeto. ${ }^{23}$

Esta corriente a nivel político se va a oponer a la llustración que pretendía que todos los hombres podían ser ciudadanos de cualquier lugar, en la medida que los unía la razón, y que ella era universal. Por el contrario para el expresivismo, y en particular para Herder, cada pueblo -Volk- tiene su propia identidad, con lo que la persona sólo puede desarrollarse en relación a esa cultura particular.

La lengua deja de ser únicamente un sistema de signos, símbolos o señales para comprender mensajes, pensamientos o sentimientos y adquiere dimensiones sociopolíticas y étnicas de alcances inimaginados. ${ }^{24}$

Siguiendo a Taylor, la otra influencia en Hegel va a ser Kant con su idea de la libertad radical, sólo delimitada en base a rígidas estructuras formales impuestas por una razón autodeterminada. Para Kant, los hombres deben regirse por imperativos derivados a priori, que sólo dependen de la aceptación de la razón. Para tal objetivo ellos sólo pueden

23 PÉREZ QUINTANA, Antonio. La Mediación de lo Posible por Libertad según Kant. Hegel ante la Crítica del Juicio. En: Aramayo, Roberto Rodríguez y Vilar, Gerard. En la Cumbre del Criticismo. Simposio sobre la Crítica del Juicio de Kant. Ed. Anthropos. España, 1992. Pág. 240.

24 RODRíGUEZ BARRAZA, Adriana. La Búsqueda Romántica de la Identidad: Macpherson y Herder. En: Revista Thémata, n 40. México, 2008. 
ser formales, y no deben tener un objeto ni estar determinados por el logro de la felicidad o el placer, como el utilitarismo ilustracionista ${ }^{25}$.

Todo el mundo ha de confesar que una ley, para valer moralmente, esto es, como fundamento de una obligación, tiene que llevar consigo una necesidad absoluta; que el mandato siguiente: no debes mentir, no tiene su validez limitada a los hombres, como si otros seres racionales pudieran desentenderse de él, y asimismo las demás leyes propiamente morales; que, por lo tanto, el fundamento de la obligación no debe buscarse en la naturaleza del hombre o en las circunstancias del universo en que el hombre está puesto, sino a priori exclusivamente en conceptos de la razón pura, y que cualquier otro precepto que se funde en principios de la mera experiencia, incluso un precepto que, siendo universal en cierto respecto, se asiente en fundamentos empíricos, aunque no fuese más que en una mínima parte, acaso tan sólo por un motivo de determinación, podrá llamarse una regla práctica, pero nunca una ley moral. ${ }^{26}$

Aquí va a jugar un papel importantísimo la voluntad moral, en la medida que una voluntad imperfecta va a ser orientada hacia objetos externos no delimitados por la razón. Esta voluntad no va a ser libre, en la medida que va a verse guiada por intereses egoístas ${ }^{27}$ (esto va a ser de suma importancia en Hegel), por el contrario la voluntad

25 Arendt logra saltar ese abismo que ha puesto Kant al dividir la moral y dejarla como ámbito práctico (esto es determinado sólo en relación a sí mismo como legislador autónomo) al hacer aparecer y explicar que lo único en que dicho mal puede sostenerse para negar los imperativos que él mismo conoce, es actuando egoístamente y haciéndolo secretamente. Con esto Arendt logra saltar el escollo que significa una moral que no considera la determinación del tiempo presente, del estar situado aquí y ahora (nunc stans), resolviéndola en una apelación a la necesidad de aparecer ante otros.

26 KANT, M. Fundamentación de la Metafísica de las Costumbres. Editorial Espasa Calpe. España, 1983. Págs. 18 y 19.

27 "Que, sin poner como condición ningún propósito a obtener por medio de cierta conducta, manda esa conducta inmediatamente. (...) No se refiere a la materia de la acción y a lo que de ésta ha de suceder, sino a la forma y al principio de donde ella sucede, y lo esencialmente bueno de la acción consiste en el ánimo que a ella se lleva, sea el éxito el que fuere. (...) Pues sólo la ley lleva consigo el concepto de una necesidad incondicionada y objetiva, $\mathrm{y}$, por tanto, universalmente válida, y los mandatos son leyes a las cuales hay que obedecer, esto es, dar cumplimiento aun en contra de la inclinación". Ídem. Pág 64 y 65. 
moral va a desear los objetos de la Razón Pura, en la medida que lo propiamente humano es ello. Este sujeto libre no se somete a ningún tipo de designio externo, a ninguna autoridad -ni siquiera Dios-, sino sólo a lo que le dice su razón, con lo que se ha producido un giro y un quiebre radical con la tradición, en cuanto no va a requerir de nada externo que lo justifique.

Es en este contexto que Hegel desarrollará su pensamiento, aunque él radicalizará muchas de las tesis de las dos vertientes, al mismo tiempo que las integrará en un sistema, que trascenderá más allá de lo que los autores de los que partió se podrían haber imaginado.

Hegel va a romper con la tradición ilustracionista de considerar a las partes como cosas separadas. Así los conceptos de identidad y diferencia, que habían complicado al pensamiento anterior a él, los va a integrar diciendo que la identidad para constituirse en tal, va a depender de la existencia de la alteridad radical, así como también esto le permitirá realizarse en cuanto concepto no estático, sino en desarrollo, en situaciones temporales. Para ello requiere de su contrario. En este sentido los opuestos, las antinomias, no se repelen, no quedan aislados, sino entran en una relación dialéctica, donde uno necesita del otro.

Hegel adquiere conciencia simultáneamente de la contradicción y la unidad, del movimiento y de lo inteligible. En lugar de oponerse a la contradicción (lo que dejaba fuera de la unidad a todos los hechos que revelan antagonismos y oposiciones) la unidad racional se transforma en unidad de los contrarios. ${ }^{28}$

Ahora bien, estos conceptos no operan en solitario respecto a la realidad; ellos dependen, a su vez, de conceptos mayores que los integren. La imagen de la Aufhebung es la de una circunferencia que gira sobre sí misma, al mismo tiempo que avanza en la historia. Esto va a ocurrir en diferentes contextos. En el caso de los conceptos de identidad y diferencia, y sus derivaciones, van a quedar integrados en el Concepto Absoluto, con el que se cerrará la Lógica. En el caso de las estructuras ontológicas de las relaciones humanas, van a quedar 
integradas en el Espíritu Absoluto, con el que se cerrará la Fenomenología del Espíritu, etc.

Ahora bien, para entender este proceso dialéctico es necesario recurrir al concepto por el cual ve Hegel la movilidad de las estructuras. Efectivamente para él nunca ocurre en el paso de una figura inferior a una superior que la primera quede simplemente superada, perdiéndose. Por el contrario, él va a hablar de Aufheben (lo que en castellano ha sido traducido por sursumisión), en el sentido que lo anterior ha sido superado, negado (en la medida que no sirve para dar cuenta de conflictos nuevos), pero lo positivo que se desplegaba en él, como resolución a problemas y conflictos anteriores, queda integrado en la nueva estructura que lo ha venido a reemplazar.

La ciencia no es aquel idealismo que, en vez del dogmatismo de la afirmación, se presenta como un dogmatismo de la seguridad o el dogmatismo de la certeza de sí mismo, sino que, por cuanto que el saber ve el contenido retornar a su propia interioridad, su actividad se sumerge más bien en este contenido, ya que es el sí mismo inmanente del contenido como lo que al mismo tiempo ha retornado a sí, y es la pura igualdad consigo mismo en el ser otro; esta actividad del saber es, de este modo, la astucia que, pareciendo abstenerse de actuar, ve cómo la determinabilidad y su vida concreta, precisamente cuando parecen ocuparse de su propia conservación y de su interés particular, hacen todo lo contrario, es decir, se disuelven a sí mismas y se convierten en momento del todo. ${ }^{29}$

Es por ello que Hegel va a vincular la libertad radical de la teoría kantiana con el expresivismo que veía la vinculación entre hombresociedad, y hombre-naturaleza. Para realizar esto va a plantear la figura del Sujeto Absoluto, que no será el hombre particular kantiano ${ }^{30}$, que nunca logra abandonar su individualidad y por tanto permanece escindido siempre fuera de su contexto histórico determinado. Éste será el Sujeto Absoluto, un todo mayor que integra las subjetividades 
particulares, aunque no las anula, sino las sursume, en la medida que estas subjetividades logran su libertad y su máximo desarrollo potencial al estar en acuerdo con el logro de la libertad del Espíritu Absoluto ${ }^{31}$. Es fundamental aquí el concepto de autonomía kantiano, pues el Sujeto Absoluto va a ser libre en tanto él es Razón, o sea que sus decisiones son concordantes con la Razón. Por otra parte, este Sujeto Absoluto tiene otras figuras en niveles intermedios, por ejemplo el Estado o el Espíritu del Mundo, que integran esa libertad en un contexto cultural y lo llevan a su máximo desarrollo -y que en el caso de la política será la transición entre Sittlichkeit y Derecho-. Pero también este Sujeto Absoluto integra a la naturaleza en la medida que es imposible un desarrollo verdaderamente libre desechando o no considerando el contexto material del desarrollo individual y cultural.

Por otra parte la necesidad racional será lo que estará detrás de todos los planteamientos históricos. Efectivamente para Hegel, el Geist, en tanto Sujeto Absoluto va a depender de las figuras menores, a las que en el plano del Mercado no puede dominar totalmente. Es en el despliegue de su libertad y de su propia identidad, que ellas adquirirán sentido en relación a lo Absoluto $^{32}$. Sin embargo, esto se realiza por medio de una necesidad que en ningún caso es enajenante, sino que por el contrario se adecua perfectamente a la libertad individual, en tanto que para ser verdaderamente libre, debe ser racional (Kant). Esta necesidad que se despliega es la que rige los destinos históricos, en la medida que ningún sujeto particular puede comprender las dimensiones de su accionar mientras él acontece -sí lo podrá hacer luego de acontecido, ése es el negocio de los filósofos-, en tanto "el búho de Minerva levanta el vuelo cuando cae el atardecer". El Geist se despliega, pero para hacerlo depende de lo que nosotros hagamos, su acción no es otra que la nuestra: estamos identificados por la razón, que nos autodetermina.

\footnotetext{
31 "En la obra del espíritu universal los estados, pueblos e individuos se erigen, cada uno, sobre su determinado principio particular, que tiene su realidad y su despliegue en su constitución y en toda la extensión de su situación real, y del cual son conscientes y en cuyo interés trabajan. Pero al mismo tiempo son miembros e instrumentos inconscientes de aquel trabajo interior, en el que esas configuraciones desaparecen mientras el espíritu en y por sí prepara y elabora el pasaje a su próximo estadio superior". Idem. Parágrafo 344.

32 Respecto a este punto véanse los parágrafos 207 y 208 de la misma obra.
} 
Esta última idea es de tremenda importancia en la teoría hegeliana, pues él va a rechazar y superar el panteísmo de la generación romántica a través de ella.

Ahora bien, Hegel vaciará estos conceptos ontológicos en su teoría política.

La noción de autonomía kantiana será la que le permitirá mediar y alcanzar la unidad con el Estado necesaria para ayudar a los individuos a lograr su satisfacción individual ${ }^{33}$. Por el contrario, para Hegel, como esta autonomía no va a estar vacía de contenido, sino que ese contenido va a ser la racionalidad desplegada y que es propia del Geist, no van a existir escisiones entre una voluntad libremente determinada y los intereses que el Estado establezca para las personas, aun cuando en momentos críticos dichas voluntades puedan levantar las banderas de la particularidad, amenazando la comunidad. Esa racionalidad va a ser el logro de la sustancia ética de las comunidades o culturas, la Sittlichkeit.

Para Hegel la teoría ética kantiana va a tener dos defectos: en primer lugar va a estar vacía de contenido, y en segundo va a ser la moralidad o ética de un individuo. Sin embargo, él no la va a rechazar, sino la va a sursumir bajo un concepto más amplio, éste es la Sittlichkeit.

Ella nace en Grecia, en las Polis, como ya vimos. Pero para Hegel esto se va a romper por el provincialismo de los deberes éticos. Para ser útiles al Geist no pueden ser sólo para un pueblo o una ciudad, deben elevarse a un rango de universalidad mayor. Esto será lo que mostrará Sócrates ${ }^{34}$, en la medida que viviendo en una cultura con una Sittlichkeit fuerte, pedirá valores más universales que no se apliquen sólo a lo que creen en cierta cultura particular; él va a buscar una Sittlichkeit universal, que es el destino necesario del Geist. Desde entonces emergerá cada vez con más fuerza la Moralität, la visión kantiana de la ética, en tanto ética individual. Así va a haber épocas en que la Sittlichkeit va a llegar a niveles tan bajos (ninguna identidad social, descomposición de los valores que dieron vida a la comunidad, conflictos incontrolables

33 Véase parágrafo 187 de la misma obra y La Teoría del Derecho, los Deberes y la Religión para la Clase Inferior. Deberes para Consigo. En: HEGEL, G.W. Escritos Pedagógicos.

${ }^{34}$ Véase la figura del alma bella en la Sección del Espíritu en Fenomenología del Espíritu. 
entre las particularidades, etc.) que la Moralität de algunos va a ser superior en jerarquía política y ontológica que la Sittlichkeit ${ }^{35}$.

Esta Sittlichkeit va a permitir que los individuos logren su realización plena, en cuanto que el fin de ellos es la vida en una comunidad donde su autonomía quede integrada y pueda desplegarse. Esta va a ser la razón de que Hegel rechace el Estado de Naturaleza de los pensadores ilustracionistas y el Contrato Social: no puede haber libertad donde no hay comunidad, pues no hay qué ofrecer, así como tampoco pueden existir valores, pues ellos son asignados socialmente.

Ahora bien, esta Sittlichkeit va a tener que ser puesta por los Estados, en la medida que ellos serán los garantes de mantener la identidad de la cultura de una comunidad, y evitar la desintegración de ella por medio de la absolutización de la particularidad de alguna visión.

Hasta ahora es bastante claro que la crisis actual ha dependido del curso atomista al que ha devenido nuestra sociedad. Hegel, al haber integrado en su teoría elementos que superan las particularidades, podría ser útil para pensar la idea de Universidad en la actualidad.

La polémica sobre la Universidad está centrada en el carácter creativo del Espíritu Absoluto expresado en dicha institución en que radica el espíritu de la Nación.

Como lo señala Lyotard en la Condición Postmoderna:

La gran función que las universidades tienen que realizar, es «exponer el conjunto de conocimientos y hacer que aparezcan los principios al mismo tiempo que los fundamentos de todo saber» pues «no existe capacidad científica creadora sin espíritu especulativo» (...). La especulación es el nombre que aquí lleva el discurso sobre la legitimación del saber científico. Las Escuelas son funcionales; la universidad es especulativa, es decir, filosófica (...). Esta filosofía debe restituir la unidad de los conocimientos dispersos en ciencias particulares en los laboratorios y en las enseñanzas pre-universitarias; sólo lo puede hacer en un juego de lenguaje que los enlaza unos a otros como momentos en el devenir del espíritu y, por tanto, en una narración o más bien en

\footnotetext{
35 Hegel va a poner como ejemplo a los Dictadores romanos.
} 
una metanarración racional. La Enciclopedia de Hegel (1817-27) tratará de satisfacer ese proyecto de totalización, ya presente en Fichte y en Schelling como idea del Sistema. ${ }^{36}$

Es por ello que el objetivo de la Universidad es especial en el campo del conocimiento. A diferencia de los Gimnasium o de la idea de Instituto Real, la Universidad expresa la unidad de los contrarios: la libertad del pensamiento expresada en la Filosofía en sus distintas ramas $^{37}$ y la adecuación a la forma objetiva de la realidad expresada en las ciencias positivas.

Debido a esto, para Hegel la Bildung conlleva inmanentemente la disciplina como constituyente esencial de ella:

El derecho de los padres sobre el arbitrio de los hijos está determinado por el fin de mantenerlos disciplinados y educarlos. La finalidad del castigo no es la justicia como tal, sino que es de naturaleza subjetiva, moral, es la intimidación de la libertad aún prisionera en la naturaleza y la exaltación de lo universal en su conciencia y su voluntad. ${ }^{38}$

Hegel cree que la libertad alcanza su máxima realización cuando conoce y quiere los fines universales que implica su adecuación al destino histórico que le ha tocado vivir en el Volkgeist, que cuaja en el Estado. Es por ello que la Universidad expresa esta universalidad y voluntad de lo nacional. Al igual que en el concepto de educación kantiano, Hegel piensa en la necesidad de que el pensamiento se desarrolle según reglas autónomas:

36 LYOTARD, J.F. La Condición Postmoderna. Ed. Cátedra. Argentina, 1991. Capítulo Los Relatos de Legitimación del Saber. En http://www.uruguaypiensa.org.uy/ imgnoticias/690.pdf.

37 "Por lo demás, está suficientemente determinado de qué ciencias debe constar la filosofía; lo universal totalmente abstracto pertenece a la Lógica, con todo lo que de ello también comprendía en sí, en otro tiempo, la metafísica; lo concreto se divide en Filosofía de la Naturaleza, que sólo versa sobre una parte del todo, y en Filosofía del Espíritu, a la que pertenecen, además de la psicología junto con la antropología, la teoría del derecho y de los deberes, también la estética y la filosofía de la religión; se ha de añadir todavía la historia de la filosofía." Acerca de la exposición de la filosofía en las Universidades. En: HEGEL, G.W. Escritos Pedagógicos. Pág. 87.

38 HEGEL, G.W.F. Op. Cit. 2004. Parágrafo 174. 
Únicamente por la educación el hombre puede llegar a ser hombre. No es, sino lo que la educación lo hace ser. Se ha de observar que el hombre no es educado más que por hombres, que igualmente están educados. De aquí, que la falta de disciplina y de instrucción de algunos, los hace también, a su vez, ser malos educadores de sus alumnos. Si un ser de una especie superior recibiera algún día nuestra educación, veríamos entonces lo que el hombre pudiera llegar a ser. Pero como la educación, en parte, enseña algo al hombre y, en parte, lo educa también, no se puede saber hasta dónde llegan sus disposiciones naturales. Si al menos se hiciera un experimento con el apoyo de los poderosos y con las fuerzas reunidas de muchos, nos aclararía esto lo que puede el hombre dar de sí. Pero es una observación tan importante para un espíritu especulativo, como triste para un amigo del hombre, ver cómo los poderosos, la mayor parte de las veces, no se cuidan más que de sí y no contribuyen a los importantes experimentos de la educación, para que la naturaleza avance un poco hacia la perfección. ${ }^{39}$

La Universidad une la universalidad y la particularidad, el espíritu nacional y la libertad (y autonomía) individual, el conocimiento pragmático de las ciencias positivas y el abstracto de la filosofía. La Universidad como realización final y superior del destino histórico del Estado-Nación moderno es el cúlmine de los sueños ilustrados y de los logros del mundo antiguo, pero también es desgarrada por las contradicciones que la modernidad engendra en su desarrollo tecnológico. Ese es el problema de la Universidad actual, pero también su desafío. ¿Cómo se resuelve en el ámbito de una política que sobrevalora el ámbito económico? ¿Quiénes son los actores llamados a realizar esta actualización? ¿De qué modo plasman su concepto de virtud en su modelo de humanidad? Por nombrar algunas interrogantes que Hegel nos lleva a plantearnos, sin afán de agotar los problemas ni acotarlos. Pues todos ellos van más allá de lo que nos puede aportar la lectura e interpretación de los textos filosóficos. Son resultado de esa praxis que para Hegel es el momento que la filosofía no puede acotar.

39 KANT, M. Sobre Pedagogía. En: Sobre Educación. Ed. Daniel Jorro. Madrid, 1911. 


\section{Bibliografía}

ARENDT, Hannah. La Crisis en la Educación. En: Entre el Pasado y el Futuro. Ocho Ejercicios de Reflexión Política Ed. Península, España, 1996.

AUBENQUE, Pierre. Aristóteles y el Liceo. En: La Filosofía Griega, Siglo XXI. Argentina, 2002.

CORDUA, Carla. El Mundo Ético, España, 1997.

FOUCAULT, Michel. Historia de la Sexualidad. Tomo 2. El Uso de los Placeres, Siglo XXI. España, 1994.

HEGEL, G.W.F. Principios de la Filosofía del Derecho, Ed. Sudamericana, Buenos Aires, 2004.

HEGEL, George Wilhem. Fenomenología del Espíritu, Ed. FCE. España, 1985. Escritos Pedagógicos. En: www.librodot.com.

HYPPOLITE, J. Introducción a la Filosofía de la Historia de Hegel, Ed. Caldén, Uruguay, 1981.

JAEGER, Werner. Paideia. FCE. México, 2002.

LEFEBVRE, Henri. ¿Qué es la Dialéctica? Ed. Dédalo, Argentina, 1959.

LYOTARD, J.F. La Condición Postmoderna. Ed. Cátedra, Argentina, 1991.

KANT, M. Sobre Pedagogía. En: Sobre Educación. Ed. Daniel Jorro, Madrid, 1911.

Fundamentación de la Metafísica de las Costumbres. Editorial Espasa Calpe, España, 1983.

KOJÈVE, A. La Dialéctica del Amo y el Esclavo. Ed. Leviatán, Argentina, 2006.

PÉREZ QUINTANA, Antonio. La Mediación de lo Posible por Libertad según Kant. Hegel ante la Crítica del Juicio. En: Aramayo, Roberto Rodríguez y Vilar, Gerard. En la Cumbre del Criticismo. Simposio sobre la Crítica del Juicio de Kant. Ed. Anthropos. España, 1992.

RODRÍGUEZ BARRAZA, Adriana. La Búsqueda Romántica de la Identidad: Macpherson y Herder. En: Revista Thémata, N 40. México, 2008.

SOBARZO, Mario. Anánkê. Historia y Necesidad. En Nombrar el Devenir. Filosofía de la Historia, Memoria y Política. Pablo Aravena (editor). Ediciones Escaparate. Concepción, Chile, 2009.

TAYLOR, Charles. Hegel y la Sociedad Moderna. Fondo de Cultura Económica. México, 1983.

VERNANT, J.P. Entre la Vergüenza y la Gloria en: El Individuo, la Muerte y el Amor en la Antigua Grecia. Editorial Paidós, España, 2001. 
